\title{
SIFAT PASTA PATI MILLET (Pennisetum glaucum (L.) R. Br.) TERMODIFIKASI HEAT MOISTURE TREATMENT UNTUK PEMBUATAN SOHUN
}

\author{
Retno Widyastuti ${ }^{11}$ \\ 1)Fakultas Pertanian, Program Studi Teknologi Hasil Pertanian, Universitas Veteran Bangun \\ Nusantara, JI. Letjend S. Humardani No. 1 Jombor Sukoharjo, Telp (0271) 593156, email : \\ javaretno@gmail.com
}

\begin{abstract}
Abstrak
Millet memiliki kandungan pati yang cukup tinggi sehingga dapat dijadikan alternatif sumber karbohidrat. Produk olahan pati yang dikenal dan disukai masyarakat Indonesia adalah berupa mi (sohun). Pati millet alami diketahui kurang stabil terhadap pengadukan dan pemanasan sehingga perlu adanya perbaikan sifat pati yaitu dengan modifikasi pati. Dalam penelitian ini akan dievaluasi karakter pati millet termodifikasi heat moisture treatment (HMT) dengan variasi perlakuan suhu dan waktu pemanasan yang sesuai untuk pembuatan sohun. Pati millet dikondisikan pada kadar air 25\% dan pemanasan 100, 130 dan $150{ }^{\circ} \mathrm{C}$ selama 3, 5 dan 7 jam dengan oven. Sifat pasting pati millet termodifikasi dianalisis kemudian dipilih pati yang sesuai untuk pembuatan sohun. Pati dipilih dengan karakter pasta yang stabil terhadap pengadukan dan pemanasan. Hasil penelitian menunjukan pati millet termodifikasi dengan perlakuan suhu $100{ }^{\circ} \mathrm{C}$ selama 7 jam memiliki karakter yang mendekati pati ideal untuk pembuatan sohun. Ditunjukan dengan viskositas puncak dan viskositas breakdown lebih rendah dibanding pati millet tanpa modifikasi HMT yaitu (2951 cP dan $71 \mathrm{cP})$, memiliki nilai viskositas pasta dingin (3695 cP).
\end{abstract}

Kata kunci : modifikasi HMT, pati millet, RVA, sifat pasting

\begin{abstract}
Improve the consumption of millet to vermicelli promoted for food diversification. Millet starch less stable of stirring and heating. Starch modification can improve the quality. In this research to evaluate pasting character of millet starch modified by heat moisture treatment which suitable for vermicelli. Heat moisture treatment conditioned at 25\% moisture content and heating 100, 130 and $150{ }^{\circ} \mathrm{C}$ for 3, 5 and 7 hours with oven. Crystalline and starch paste properties of modified starch were analyzed and then selected to vermicelli. The suitable starch for vermicelli which stable paste of stirring and heating and high gel strength. The results show modified starch with $100{ }^{\circ} \mathrm{C}$ for 7 hours has an ideal for vermicelli. Shown by lower peak viscosity and viscosity breakdown (2951 cP and $71 \mathrm{cP}$ ), high final viscosity (3695 cP).
\end{abstract}

Keywords : Heat moisture treatment, millet starch, RVA, pasting properties

\section{PENDAHULUAN}

Millet dapat dijadikan alternatif diversifikasi pangan pokok sumber karbohidrat. Millet merupakan salah satu bahan pangan pokok lokal yang terdapat Indonesia terutama di wilayah Nusa Tenggara. Tanaman millet mampu tumbuh adaptif, tidak membutuhkan banyak air dan bahan kimia pupuk. Biji millet kaya akan zat besi dan antioksidan serta berpotensi sebagai zat antikanker dan antidiabetes.

Pemanfaatan millet masih kurang diketahui masyarakat, sehingga diperlukan pengembangan produk berbasis millet yang dikenal masyarakat seperti sohun. Sohun adalah salah satu produk makanan kering yang dibuat dari pati. Untuk menghasilkan sohun dengan kualitas baik diperlukan bahan baku yang sesuai. Berdasarkan penelitian karakter pati yang sesuai untuk pembuatan sohun ialah pati dengan ukuran granula kecil, kandungan amilosa tinggi, daya kembang dan kelarutan terbatas serta memiliki kurva brabender tipe $\mathrm{C}$.

Pati millet alami diketahui memiliki viskositas puncak yang tinggi namun 
mengalami penurunan cepat selama pemanasan dan pengadukan serta daya kembang dan kelarutan yang tinggi sehingga tidak sesuai untuk pembuatan sohun. Oleh karena itu perlu dilakukan peningkatan sifat fungsional pati sebagai bahan baku sohun. Peningkatan sifat fungsional dapat dilakukan melalui modifikasi pati, salah satunya dengan metode heat-moisture treatment.

\section{Heat-moisture treatment ialah} memanaskan pati diatas suhu gelatinisasi dengan kadar air terbatas sehingga pati hanya mengalami gelatinisasi sebagian. Dampaknya akan berpengaruh pada konformasi molekul yang disertai dengan perubahan karakteristik pati. Perubahan pati dipengaruhi oleh kondisi perlakuan seperti suhu, kadar air dan waktu pemanasan maupun karakter awal pati seperti kandungan amilosa.

Penelitian terkait heat-moisture treatment telah banyak dilakukan diantaranya pada pati kentang pada suhu $110{ }^{\circ} \mathrm{C}$ dengan proses stirring selama 30 menit pada kadar air $30 \%$ (Zhang et al., 2013) dan pati kacang hijau pada suhu $120^{\circ} \mathrm{C}$ selama 12 jam pada kadar air 15-35\% (Li et al., 2011).

Perubahan karakter pati dengan berbagai kondisi perlakuan diantaranya mampu menurunkan kelarutan dan daya kembang pati sorghum dengan kondisi HMT kadar air $21 \%$ selama 12 jam dengan suhu $100^{\circ} \mathrm{C}$ (Haryani dkk., 2015), peningkatan nilai kapasitas penyerapan air, penurunan nilai swelling volume, kecenderungan peningkatan freeze-thaw stability, kelarutan, suhu awal gelatinisasi, viskositas puncak, viskositas pasta panas, viskositas pasta dingin dan viskositas setback pada pati talas (Fetriyuna dkk., 2016), meningkatkan gel hardness dan menurunkan adhesieveness (Sun et al., 2013), menurunkan derajat pembengkakan dan kelarutan serta meningkatkan stabilitas termal (Klein et al., 2013).

Perubahan sifat fisikokimia pati termodifikasi tergantung pada sifat asal pati dan kondisi modifikasi yang diterapkan. Metode HMT telah diterapkan untuk meningkatkan kualitas bihun yang terbuat dari pati sorghum (Haryani dkk., 2015) Hasil penelitian menunjukan bahwa modifikasi HMT mengakibatkan perubahan kelarutan dan daya kembang pati sehingga memiliki potensi sebagai bahan substitusi pati beras pada pembuatan bihun. Perubahan karakter pati tipe $B$ maupun tipe $C$ diketahui memiliki sifat yang lebih tahan terhadap panas dan pengadukan sehingga sesuai untuk diaplikasikan untuk produk sohun.

Pada penelitian ini akan dilakukan modifikasi pati millet dengan metode HMT pengaturan kadar air $25 \%$ dengan variasi suhu $\left(100^{\circ} \mathrm{C}, 130^{\circ} \mathrm{C}, 150{ }^{\circ} \mathrm{C}\right)$ dan waktu $(3$ jam, 5 jam, 7 jam) untuk menghasilkan pati millet termodifikasi yang karakteristiknya sesuai untuk pembuatan sohun. Informasi yang diperoleh diharapkan dapat dijadikan dasar untuk pengembangan produksi makanan berbasis pati millet.

\section{BAHAN DAN METODE}

\section{Bahan}

Bahan utama yang digunakan untuk penelitian ini adalah biji millet yang jenis pearl millet (Pennisetum glaucum (L.) R. Br.) berwarna kekuningan yang diperoleh dari pasar Beringharjo Yogyakarta.

\section{Metode \\ Ekstraksi Pati Millet}

Pati millet diperoleh dengan cara biji millet diblender dengan menambahkan air (1:3) kemudian diendapkan semalam. Pemblenderan dilakukan sebanyak 3 kali selama masing-masing 30 detik, 1 menit dan 1 menit. Pati yang diperoleh dideproteinasi dengan $\mathrm{NaOH} 0,1 \mathrm{~N}$ semalam kemudian dicuci dengan aquades dan dinetralkan dengan $\mathrm{HCl}$ hingga mencapai $\mathrm{pH}$ 7. Endapan pati deproteinasi dikeringkan selama 6 jam dalam cabinet dryer suhu $55^{\circ} \mathrm{C}$. pati millet kering disimpan untuk perlakuan selanjutnya.

\section{Proses Heat-moisture Treatment}

Pati millet dianalisis kadar airnya sebagai dasar penambahan air sampai dengan $25 \%$. Pati yang telah diatur kadar airnya diletakkan dalam loyang yang ditutup plastik kemudian disimpan dalam refrigerator suhu $5^{\circ} \mathrm{C}$ selama 
12 jam agar kadar air seragam. Setelah kadar air merata pati dimasukan dalam botol jam bertutup lalu dipanaskan dalam oven pada variasi suhu $100{ }^{\circ} \mathrm{C}, 130{ }^{\circ} \mathrm{C}$ dan $150{ }^{\circ} \mathrm{C}$ selama 3 jam, 5 jam dan 7 jam. Kemudian pati yang telah termodifikasi dikeringkan dalam cabinet dryer selama 4 jam pada suhu $55^{\circ} \mathrm{C}$. lalu pati disimpan untuk dianalisis selanjutnya.

\section{Analisis Kristalinitas}

Analisis kristalinitas pati millet dilakukan menggunakan alat X-RD untuk menera spektra kristalin pada pati millet dinyatakan dalam persen (\%). Pola struktur pati millet alami dan pati millet termodifikasi dilihat dari puncak yang dihasilkan. Kristalinitas (\%) dinyatakan sebagai persentase rasio dari daerah difraksi puncak dengan difraksi total.

Analisis sifat pasting (William et al., 2019)

Pengukuran karakteristik pasting dilakukan menggunakan Rapid Visco Analyzer (RVA) tipe RVA-S4 dengan profil analisis standar 2. Sebanyak $3.5 \mathrm{~g}$ sampel (kadar air disesuaikan 14\%) dicampur dengan $25 \mathrm{ml}$ akuades di dalam wadah sampel (canister). Wadah berisi sampel selama 1 menit pertama diputar 19 pada kecepatan $160 \mathrm{rpm}$ dan suhu $50^{\circ} \mathrm{C}$. Selanjutnya, sampai menit ke 8.5, suhu pemanasan dinaikan dari $50^{\circ} \mathrm{C}$ menjadi $95^{\circ} \mathrm{C}$. Suhu dijaga konstan pada $95^{\circ} \mathrm{C}$ selama 5 menit (sampai menit ke 13.5). Setelah pemanasan konstan, suhu diturunkan menjadi $50^{\circ} \mathrm{C}$ (pada menit ke 21) dan dipertahankan pada suhu $50^{\circ} \mathrm{C}$ selama 2 menit (sampai menit ke 23). Dari kurva RVA akan diperoleh nilai dari suhu awal pasting, suhu viskositas maksimum viskositas puncak, viskositas pasta panas dan viskositas akhir, viskositas breakdown dan viskositas setback.

\section{Rancangan percobaan}

Rancangan percobaan yang digunakan rancangan acak lengkap. Karakteristik pati termodifikasi HMT menggunakan dua faktor yaitu suhu pemanasan $\left(100{ }^{\circ} \mathrm{C}, 130{ }^{\circ} \mathrm{C}, 150\right.$ $\left.{ }^{0} \mathrm{C}\right)$ dan waktu (3 jam, 5 jam, 7 jam). Pengambilan data dilakukan dengan dua kali ulangan batch dan tiga kali ulangan analisis. Data yang diperoleh dianalisa statistik dengan metode one way analysis of variance (ANOVA), jika terdapat perbedaan antar perlakuan maka dilanjutkan dengan beda uji beda nyata menggunakan analisa duncan's multiple range test (DMRT) pada taraf signifikansi 95\%. Pengolahan data untuk uji statistik menggunakan program SPSS 16.0.

\section{HASIL DAN PEMBAHASAN}

\section{Difraksi Sinar-X}

Pola difraksi sinar $X$ kristalin pati millet alami yang memiliki tiga puncak utama (strongest peaks) pada sudut $2 \theta$ yaitu $18,04^{0}$; $17,16^{\circ}$ dan $15,06^{\circ}$ terbentuknya puncak utama pada sudut tersebut menandakan pati millet alami memiliki kristal dengan tipe A ditandai dengan adanya dua puncak yang sama pada sudut difraksi $2 \theta$. Hasil analisis pola difraksi sinar $X$ dengan $X-R D$ menunjukan data tentang kristalinitas relatif $(\mathrm{Xc})$. Xc pati millet alami dari hasil difraksi sinar $X$ adalah $12,83 \%$. Pola difraksi sinar-X dapat dilihat pada Gambar 1.

Perlakuan pemanasan dengan kadar air terbatas menyebabkan menurunnya intensitas pada berbagai puncak. Penurunan puncak ini akibat proses pemanasan yang dapat menyebabkan terbukanya struktur rantai heliks ganda pada daerah kristalin amilopektin. HMT mengubah pengaturan ulang rantai heliks ganda yang dapat meningkatkan keteraturan (intensitas difraksi sinar $X$ naik) atau menurunkan keteraturan daerah kristalin (intensitas difraksi sinar $X$ turun) tergantung pada kondisi HMT yang diterapkan. Tipe kristal pati millet termodifikasi tidak mengalami perubahan, sama halnya seperti pati millet alami, yaitu tipe A.

Karakter pasta (Rapid Visco Analyzer)

Pati millet alami memiliki profil pasta tipe A yang dicirikan dengan viskositas puncak tinggi diikuti oleh penurunan viskositas secara cepat ketika proses pemanasan dilanjutkan 
(breakdown viscosity) dan viskositas balik (setback viscosity) yang rendah pada saat penurunan suhu. Profil pasta pati millet alami dan pati millet termodifikasi disajikan pada gambar 2 .

Proses modifikasi HMT mengakibatkan perubahan suhu awal pasting yaitu dari $76,65^{\circ} \mathrm{C}$ menjadi $80,72^{\circ}$ $84,37^{\circ} \mathrm{C}$. Peningkatan suhu pasting ini diduga karena granula yang semakin rigid akibat perubahan daerah kristalin pati dari perlakuan pemanasan oven dengan variasi suhu dan waktu pemanasan. Hasil penelitian sejalan dengan Sun et al., 2014 pada pati sorgum dimana suhu suhu awal pasting setelah modifikasi HMT pemanasan oven $100^{\circ} \mathrm{C}$ selama 10 jam dengan pengaturan kadar air $20 \%$ dan $25 \%$ meningkat dari $75,25^{\circ} \mathrm{C}$ menjadi $80^{\circ} \mathrm{C}$.

Pati millet termodifikasi mengalami penurunan viskositas puncak dibanding pati alami. Semakin meningkat suhu dan waktu perlakuan, viskositas puncak semakin menurun. Penurunan nilai viskositas puncak paling besar terjadi pada pati millet yang diberi pelakuan pemanasan suhu $130^{\circ} \mathrm{C}$ Selama 7 jam yaitu $1399 \mathrm{cP}$. Penurunan viskositas mengindikasikan bahwa granula pati HMT memiliki daya mengembang dan daya penyerapan air lebih rendah (Haryani dkk, 2015). Hal ini disebabkan oleh struktur granula pati yang makin rigid akibat dari interaksi inter dan intramolekul granula yang semakin kuat dan rapat sehingga menghambat penetrasi air sehingga pembengkakan menjadi terbatas. Adanya interaksi rantai amilosa-amilosa dengan rantai amilosa-amilopektin yang terjadi selama proses HMT menyebabkan ikatan antar molekul semakin rapat dan air semakin sulit untuk penetrasi ke granula.

Pengukuran viskositas pasta panas dan viskositas breakdown bertujuan mengetahui pengaruh perlakuan proses HMT terhadap kestabilan pasta pati selama proses pemanasan. Pengaruh HMT mengakibatkan penurunan viskositas pasta panas dan viskositas breakdown pada pati millet. Viskositas breakdown merupakan salah satu faktor penting ketika diaplikasikan pada produk yang menunjukan kestabilan pasta pati terhadap pemanasan. Semakin kecil nilai viskositas breakdown maka pati semakin stabil pada kondisi pemanasan. Yadav et al., (2013) menunjukan bahwa semua parameter pada karakterisasi pasta pati indian water chesnut yaitu peak viscosity, viskositas pasta panas, viskositas breakdown, dan viskositas setback menunjukan penurunan, hal ini sesuai dengan hasil perlakuan HMT pada pati millet. Penurunan nilai viskositas breakdown dan viskositas setback pelakuan HMT mengindikasikan kestabilan pada pengadukan pada pasta pati termodifikasi.

Berdasarkan hasil uji statistik diperoleh nilai viskositas pasta dingin yang tertinggi pada perlakuan HMT suhu $100^{\circ} \mathrm{C}$ selama 7 jam. Viskositas setback adalah derajat reasosiasi atau pembentukan kembali ikatan-ikatan hidrogen yang telah terputus antara molekul pati yaitu molekul amilosa dan amilopektin ketika mengalami pendinginan. Pendinginan lebih lanjut dapat menyebabkan pati membentuk pati membentuk gel dengan ikatan amilosa dan amilopektin yang semakin kuat dan kompak. Kemampuan membentuk gel yang tinggi menunjukan kestabilan terhadap proses pengadukan.

\section{SIMPULAN}

Pati millet alami memiliki kestabilan viskositas yang rendah. Modifikasi pati millet dengan teknik HMT mengubah profil 
pasta pati menjadi lebih stabil. Pati millet termodifikasi HMT dengan suhu pemanasan oven $100{ }^{\circ} \mathrm{C}$ selama 7 jam menunjukan profil yang dinilai sesuai untuk pembuatan sohun, yaitu memiliki viskositas puncak dan viskositas breakdown lebih rendah dibanding pati alami (2951 cP dan $71 \mathrm{cP}$ ), memiliki nilai viskositas pasta dingin tinggi (3695 cP) dan memiliki nilai gel hardness paling tinggi $(0,47 \mathrm{~N})$.

\section{DAFTAR PUSTAKA}

Fetriyuna, Marsetio, Pratiwi R.L., 2016. Pengaruh Lama Modifikasi HeatMoisture Treatment (HMT) terhadap Sifat Fungsional dan Sifat Amilografi Pati Talas Banten (Xanthosoma undipes K. Koch). Jurnal Penelitian Pangan Vol. 1.1: 44-50

Haryani K., Hadiyanti, Hargono, Handayani N.A. 2015. Sifat Fisikokimia Pati Sorghum Varietas Merah dan Putih Termodifikasi Heat Moisture Treatment (HMT) untuk Produk Bihun Berkualitas. Prosiding Seminar Nasional Teknik Kimia "Kejuangan". Pengembangan Teknologi Kimia untuk Pengolahan Sumber Daya Alam Indonesia. Hal. B7.1 - B7.6

Klein B. Pinto V.Z., Vanier N.L., Zavareze E.D.R., Colussi R., Evangelho J.A.A.A. 2013. Effect of single and dual heatmoisture treatment on properties of rice, cassava and pinhao straches. Carbohydrate Polymers 98. : 15781584.

Li, S., Ward R dan Gao Q. 2011. Effect of heat moisture treatment on the formation and physicochemical properties of resistant starch from mung bean (Phaselous radiatus) starch. Food hydrocolloids, 25 (7) : 1702-1709

Sun Q., Wang T., Liu X., Zhao Y. 2013. The effect of heat moisture treatment on physicochemical properties of early indica rice. Food Chemistry 14 : 853857.

Sun Q., Han Z., Wang L., dan Xiong L., 2014. Physicochemical differences between sorghum starch and sorgum flour modified by heat-moisture treatment. Food Chemistry $145: 756-764$

William G., Ansah K., Agbenorhevi J., Oduro I., Bobobee E. 2019. Characterization of starch from new cassava accesion at different maturity. Journal of food security Vol. $7:$ 170-174

Yadav B.S. Gulera P dan Yadav R.B. 2013. Hydrothermal modification of indian water chestnut starch : influence of heat-moisture treatment and annealing on the physicochemical gelatinization and pasting characteristics. LWT-food Science and technology, $53:$ :211-217

Zhang B., Zhaoa Y., Lia X., Zhang P., Xieb F., Chena L.,. 2013. Effects of amylose and phosphate monoester on aggregation structures of heatmoisture treated potato starches. Carbohydrate Polymers 103 : 228-233. 
Widyastuti. 2021

\section{LAMPIRAN}
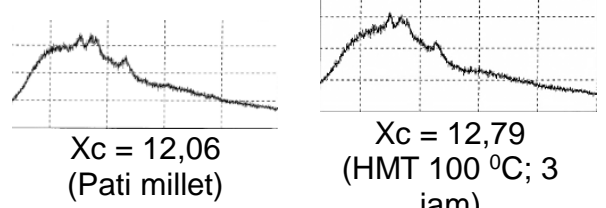

(HMT $100^{\circ} \mathrm{C} ; 3$

(Pati millet)

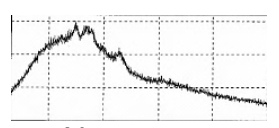

$\mathrm{Xc}=12,08$

(HMT $100^{\circ} \mathrm{C} ; 5$

jam)

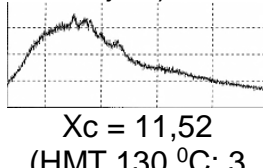

(HMT $130^{\circ} \mathrm{C} ; 3$

jam)

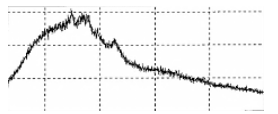

$\mathrm{Xc}=11,38$

(HMT $130^{\circ} \mathrm{C} ; 7$

jam)

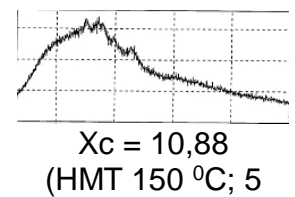

jam)

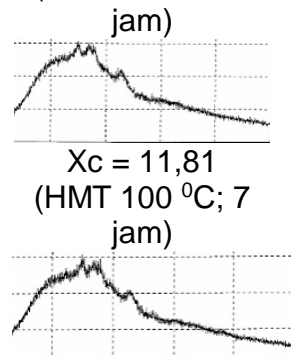

$\mathrm{Xc}=11,85$

(HMT $130{ }^{\circ} \mathrm{C} ; 5$

jam)

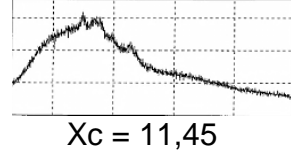

(HMT $150{ }^{\circ} \mathrm{C} ; 3$

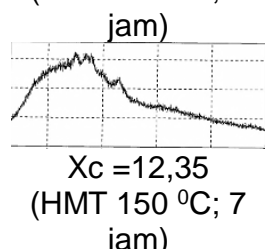

Gambar 1. Pola difraksi sinar-X dan kristalinitas relatif $(\mathrm{Xc})$ pati alami dan pati termodifikasi Heat Moisture Treatment

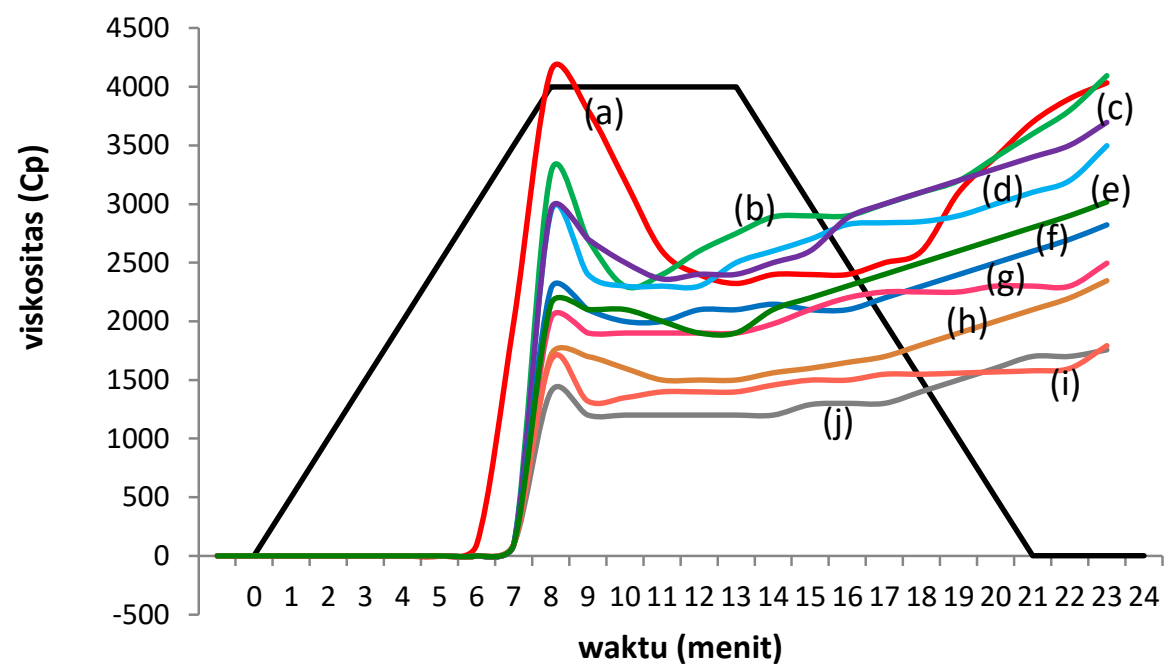

Gambar 2. Profil pasta pati millet alami dan pati millet termodifikasi

Keterangan :

(a)pati millet; (b)HMT $100^{\circ} \mathrm{C} 3$ jam;(c) HMT $100^{\circ} \mathrm{C} 7$ jam; (d)HMT $100^{\circ} \mathrm{C} 5$ jam; (e)HMT $1500^{\circ} \mathrm{C} 7$ jam;

(f)HMT $130^{\circ} \mathrm{C} 5$ jam; (g)HMT $150^{\circ} \mathrm{C} 3$ jam; (h)HMT $130^{\circ} \mathrm{C} 3$ jam; (i)HMT $150^{\circ} \mathrm{C} 5$ jam; (j)HMT $130^{\circ} \mathrm{C} 7$ jam; 